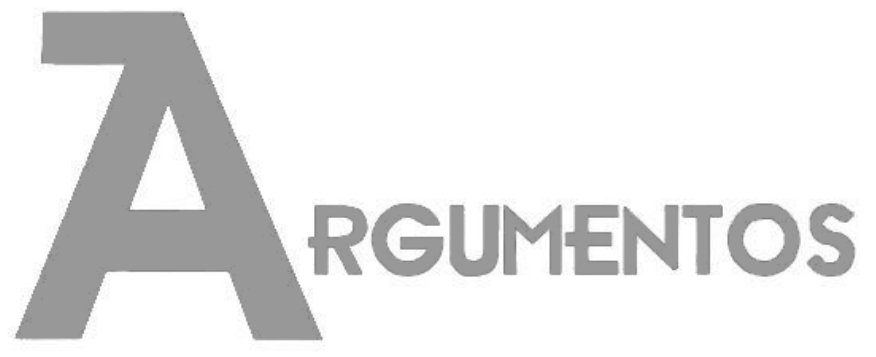

Vol. 18, n. 1, jan./jun. 2021

ISSN: 2527-2551 (online)

https://www.periodicos.unimontes.br/index.php/argumentos

\title{
Entrevista com Joaze Bernardino-Costa (UnB)
}

Recebido em: 22/01/2021

Aprovado em: 08/02/2021

No Dia da Consciência Negra, o Departamento de Ciências Sociais (DPCS) da Universidade Estadual de Montes Claros (UNIMONTES), Brasil, realizou, em caráter especial, uma entrevista virtual (live) com o sociólogo e professor Dr. Joaze Bernardino Costa $^{1}$, que atua no campo dos estudos do pós-colonialismo, das teorias decoloniais, dos intelectuais negros, das teorias da diáspora, das ações afirmativas e do trabalho doméstico, com ênfase na questão da condição das populações negras no Brasil. A entrevista foi realizada por Maria Railma Alves ${ }^{2}$ (doutora em Ciências Sociais, professora e chefe do Departamento de Ciências Sociais da UNIMONTES); Antônio Dimas Cardoso 3 (doutor em Sociologia/UNB, professor do Departamento de Política e Ciências Sociais/UNIMONTES e do Programa de Pós-Graduação em Desenvolvimento Social PPGDS/UNIMONTES); e Doriam Borges ${ }^{4}$ (doutor em Sociologia/IUPERJ, professor do Departamento de Ciências Sociais da Universidade do Estado do Rio de Janeiro - UERJ e professor colaborador do Programa de Pós-Graduação em Ciências Sociais/PPCIS/UERJ).

A entrevista com o professor Joaze Bernardino-Costa teve como objetivo integrar o conteúdo da Revista ARGUMENTOS, editada pelo Departamento de Política e

\footnotetext{
${ }^{1}$ E-mail: joazebernardino@gmail.com.

2 E-mail: railmalves@hotmail.com.

${ }^{3}$ E-mail: doriamb@gmail.com.

${ }^{4}$ E-mail: antonio.dimas@unimontes.br.
} 
Ciências Sociais (DPCS) da Universidade Estadual de Montes Claros (UNIMONTES), que nesta edição tem como objetivo analisar os principais elementos relacionados aos aspectos das desigualdades sociais e refletir sobre as discriminações étnico-raciais que permeiam a nossa sociedade.

Joaze Bernardino-Costa é professor associado do Departamento de Sociologia da Universidade de Brasília (UnB). Possui graduação em Ciências Sociais (1995), mestrado em Sociologia (1999) e doutorado em Sociologia (2007) pela Universidade de Brasília. Realizou seu pós-doutorado no Departamento de Estudos Étnicos da Universidade da Califórnia, em Berkeley (2014-2015), onde desenvolveu o projeto Pensamento Caliban no Brasil: Intelectuais Negros e o Campo das Relações Raciais à Luz das Teorias Decoloniais. Atuou como pesquisador visitante (2017) no Rutgers Advanced Institute for Critical Caribbean Studies (RAICCS - Rutgers University), onde aprimorou seus estudos sobre intelectuais negros caribenhos. Integrou a equipe da Universidade de Brasília que elaborou e propôs a Política de Ações Afirmativas para Estudantes Negros(as), Indígenas e Quilombolas nos Cursos de Pós-Graduação, aprovada em 2020. Atualmente, é o presidente da Comissão de Acompanhamento da Política de Ações Afirmativas na PósGraduação. Integra uma rede internacional de pesquisa sobre práticas de racialização e promoção da igualdade racial que engloba Brasil, África do Sul, Reino Unido e Suécia. Leciona e orienta estudantes de graduação, mestrado e doutorado.

A seguir, a transcrição da entrevista, que foi realizada no dia 20 de novembro de 2020:

Prof. Antônio Dimas Cardoso: Ao examinar alguns de seus trabalhos publicados, constata-se, em suas análises, a defesa da tese de se entender a questão de raça como categoria social - e não como uma categoria biológica. Essa sua abordagem inevitavelmente nos leva a considerar o racismo como uma doutrina que hierarquiza grupos raciais; que remete a uma "hierarquia classificatória", como você afirma. Assim, a raça, como outras dimensões da vida social, é um fator explicativo do fenômeno da desigualdade social, também no seu sentido mais estrutural. Como incorporar neste debate a questão de classe, com vistas a mudanças concretas, para além de mudanças discursivas ou normativas? 
Prof. Joaze Bernardino-Costa: Esta é uma pergunta muito importante, muito relevante. É um debate que precisa ser retomado. Muitas vezes, o debate que a gente poderia chamar de culturalista e o debate sobre identidades apagam ou ofuscam um pouco o debate sobre classes. Primeiramente, gostaria de chamar atenção para o fato de que o debate sobre classes, a meu ver, sempre esteve colocado nas discussões sobre raça. Se a gente fizer uma revisão dos projetos teóricos de intelectuais negros/as, encontraríamos essa vinculação entre raça e classe. Por exemplo, eu tenho trabalhado muito com a ideia de decolonialidade, com o projeto decolonial. O primeiro parágrafo da teorização de Aníbal Quijano (2005) fala que raça é um elemento constitutivo do capitalismo mundializado, que se inicia a partir da chegada dos europeus à América. Há uma clara articulação entre raça e classe na constituição do sistema-mundo moderno/colonial, dando origem, portanto, a uma divisão racial do trabalho em escala global. Da mesma forma, autores e autoras críticas ao Quijano vão falar da relevância da dimensão de gênero. As dimensões de gênero, classe e raça estão fortemente articuladas na formação desse sistema-mundo, desse projeto civilizatório no qual estamos.

Ramón Grosfoguel (2018) chama atenção para o fato de que a teorização de Quijano está baseada numa forte tradição de pensamento de intelectuais negros/as e indígenas que não formularam e não sistematizaram os conceitos e teorias com o mesmo grau de clareza que o próprio Quijano. Por exemplo, Oliver Cox (1959), que a gente lê muito pouco aqui no Brasil - a gente conhece muito mais o livro dele Raça, Classe e Castas, publicado em 1948 -, vai construir a ligação entre capitalismo e racismo. Estas duas dimensões são elementos constitutivos que estão na base de teóricos negros que formam e dão os elementos, os insumos, para que Aníbal Quijano formule a sua teoria da colonialidade do poder - e, nessa formulação, classe e raça são elementos constitutivos e indissociáveis. Mas podemos ir um pouco além. Por exemplo, se a gente olhar um autor como Frantz Fanon - que eu também qualifico como decolonial, mesmo que não utilize o aparato conceitual da atual teoria da decolonialidade -, ele vai falar, no final de Pele Negra, Máscaras Brancas (2008), da luta pela desalienação - esse é o termo que ele utiliza - de um negro que trabalha na construção de um porto em Abidjan, na Costa do Marfim. Ele vai falar que a luta desse negro que trabalha na construção de um porto em Abidjan é a luta contra a exploração de uma raça pela outra; contra o desprezo 
de uma parte da humanidade por outra civilização. Então, veja bem como ele traz a dimensão da exploração - da exploração, portanto, econômica, que não é simplesmente um processo que se daria no campo da cultura, da identidade ou no campo do preconceito. Assim, acho que podemos reconhecer essa vinculação entre classe e raça não somente em Fanon, mas na grande tradição dos marxistas negros. Assim, passamos também por autores como C. L. R. James, que escreveu Os Jacobinos Negros (2000), Lélia Gonzalez (1988), Beatriz Nascimento (apud Ratts, 2007), Guerreiro Ramos (1957), Abdias do Nascimento (2009), apenas para falar desses autores e autoras que estão falando de coisas semelhantes: da relevância da dimensão de classe para entender raça no Brasil, bem como da relevância da dimensão de raça para entender classe no Brasil.

Como citei o C. R. L. James, acho interessante dizer que quando ele vai para a Inglaterra, passa a ser discriminado pelos camaradas do Partido Comunista inglês. É importante percebermos como se dá esse jogo, e como que - tomando o Partido Comunista inglês como exemplo -, aquela que poderíamos chamar de esquerda ortodoxa não incorporava as dimensões de raça. E a mesma coisa se dava nos Estados Unidos. Não sei quantos tiveram a oportunidade de ler o livro O Homem Invisível, do Ralph Ellison (1980), em que, em determinado momento, o protagonista do livro é enxotado de uma reunião do Partido Comunista americano, que não estava disposto a debater as questões raciais. Neste sentido, eu poderia dizer que a incorporação da discussão de classe não tem sido um problema para quem tem discutido racismos no Brasil, mas, a meu ver, a formulação inversa não é verdadeira, no sentido de que quem tem pensado classe como categoria explicativa da realidade social brasileira e da ação política muitas vezes não tem incorporado a dimensão racial. Por exemplo, eu fiz pesquisa sobre os sindicatos das trabalhadoras domésticas no Brasil (Bernardino-Costa, 2015), e o que deixava as trabalhadoras domésticas sindicalizadas - em sua ampla maioria, mulheres negras - assustadas, estupefatas e admiradas era o fato de dirigentes e membros dos sindicatos dos bancários, dos petroleiros, etc., comparecerem aos sindicatos questionando os direitos das trabalhadoras domésticas, não querendo pagar seus direitos sociais ou uma justa remuneração, mas principalmente se referirem às trabalhadoras domésticas de forma racista. É o tipo de coisa que forma as incoerências do Brasil. 
Então, voltando à sua pergunta, na minha avaliação, não só a questão de classes está presente na formulação de muitos pesquisadores e pesquisadoras que têm estudado e lutado contra discriminação racial e racismo, mas acho que classe hoje tem sido fundamental para as feministas negras, por exemplo, pensarem a ideia de interseccionalidade. Aliás, as formulações sobre interseccionalidade, que eu considero uma teorização inovadora, importante e fundamental, em momento algum prescinde de qualquer um dos eixos de poder - seja classe, raça, gênero ou outro - para compreender a realidade e pensar na ação política. E eu acrescentaria que a classe é tão relevante nesse sentido que, quando alteramos questões que estão ligadas à política redistributiva (como, por exemplo, aumento salarial), isso tem impacto positivo inquestionável sobre a população negra. Se observarmos, por exemplo, em algum período um aumento do salário mínimo, sabemos que aquele aumento impacta direta e positivamente as mulheres negras. Então, isso é uma coisa que você operacionaliza na base do eixo econômico e que tem um impacto direto sobre a dimensão de raça. Para concluir, acho que há alguns excessos no culturalismo, mas é necessário que a gente faça essa articulação porque, afinal de contas, acho que raça está muito integrada, muito articulada à dimensão de classe. Voltando ao que falei anteriormente, apenas para enfatizar: se a gente pensa na formulação desse sistema-mundo moderno/colonial, em que nós somos a periferia desse mundo, observamos que a constituição daquilo que Immanuel Wallerstein (1974) chama de capitalismo histórico conta com o trabalho escravo e a servidão de indígenas para o progresso do capitalismo em outras localidades. Então, veja como que a dimensão racial é fundamental para o funcionamento do capitalismo. Nesse sentido, é fundamental a gente retomar, com mais ênfase, nas nossas teorizações, nas nossas pesquisas, essa dimensão de classe também para se pensar o racismo, para se pensar as desigualdades raciais e a discriminação no Brasil.

Prof. Antônio Dimas Cardoso: Nancy Fraser (2006), ao problematizar o dilema "redistribuição-reconhecimento", afirma que raça também é um modo ambivalente de coletividade, com uma face político-econômica e outra cultural-valorativa. Você concorda com essa afirmação? E, se concorda, como pensar numa concepção universalista de reconhecimento, de "redistribuição transformativa", que reduz 
desigualdade social sem pretender alimentar ainda mais a estigmatização, para além de políticas afirmativas ancoradas pelo Estado liberal?

Prof. Joaze Bernardino-Costa: Concordo, em parte, com o esquema teórico apresentado pela Nancy Fraser ao caracterizar as coletividades de raça como movimentos que fazem demandas bivalentes - ou seja, demandas por redistribuição e reconhecimento. Na formulação que ela constrói, existe um dilema para corrigir as injustiças provocadas pelo racismo. No seu esquema teórico, os 'remédios 'afirmativos estariam associados aos princípios e valores da sociedade hegemônica. Portanto, por exemplo, poderíamos dizer que as políticas de ações afirmativas alimentariam as estigmatizações sobre a população negra como uma população não apta à concorrência pelas posições meritocráticas da sociedade. Já os 'remédios 'transformativos poderiam estar associados ao que ela chama de desconstrução do modelo de classificação racial brasileiro. Eu acho que esses são caminhos que ela aponta de uma maneira bastante esquemática.

Considero que o esquema teórico elaborado por ela nos permite antecipar algumas leituras, algumas possibilidades, mas eu gostaria de pensar isso a partir da empiria e de como a empiria pode nos estimular a pensar outras formulações. Ou seja, como podemos dar um passo além do que a Nancy Fraser está falando, no sentido de que essa não é uma questão sobre a qual possamos predizer o futuro, dizer o que vai acontecer - que a ação afirmativa resultará em um aumento da estigmatização da população negra. Se o modelo teórico é dado previamente e se é um modelo fechado, estaríamos condenados ao que já sabemos hoje, portanto, seria o fim da história. Entretanto, como penso que é apenas um modelo teórico, que nos ajuda a pensar e não fecha as possibilidades históricas, vou ensaiar outras possibilidades diante das políticas de ações afirmativas.

Antes de entrar propriamente nessa reflexão, gostaria apenas de lembrar que, como vocês sabem, estou envolvido com as ações afirmativas desde o início desse debate aqui no Brasil. Estive acompanhando, muito de perto, as discussões na Universidade de Brasília, que se iniciaram de 1998 para 1999, e que culminaram na adoção da política de cotas em 2003, com implantação a partir de 2004. E, ao mesmo 
tempo, também estive em atuações de caráter nacional na UERJ. Eu fazia parte do Programa Políticas da Cor na Educação Brasileira, que era coordenado pelo professor Pablo Gentili e pelo Emir Sader. Ao mesmo tempo, também me envolvi na construção do projeto de ações afirmativas da Universidade Federal de Goiás, onde estive por nove anos como professor. E agora, mais recentemente, construímos junto com estudantes, professores/as, a política de ações afirmativas na pós-graduação para toda Universidade de Brasília. Esta política foi pensada globalmente. Não somente é uma política de acesso à pós-graduação, como também é uma política de permanência, uma vez que aprovamos uma resolução complementar que garante a concessão prioritária das bolsas para estudantes indígenas, quilombolas, negros/as e com deficiência. Somente após todos os/as candidatos/as aprovados/as pertencentes a esses grupos receberem as bolsas é que os/as demais candidatos/as aprovados/as passam a ser atendidos/as. É um projeto bastante audacioso, que está em fase de implementação.

Dito isso, voltemos ao diálogo com a Nancy Fraser. Há, efetivamente, o risco de as políticas de ações afirmativas se reduzirem ao que tenho chamado de uma espécie de multiculturalismo liberal. Ou seja, essa política pública para corrigir injustiças, via remédios afirmativos, poderia conduzir ao que podemos nomear como multiculturalismo liberal - como políticas para que a população negra se conforme ao modelo liberal como consumidora. Eu gosto muito do texto do Stuart Hall (2003), A Questão Multicultural, em que ele traça, no momento em que ele escreve o texto, sete adjetivações da ideia de multiculturalismo, e uma das adjetivações é a ideia de multiculturalismo liberal, que é o multiculturalismo de mercado - aquele multiculturalismo para criar um mercado específico para a população negra. Tivemos e temos isso aqui no Brasil. Sabonete de tal marca para pessoas que têm a pele preta e pele morena, shampoos específicos etc. Eu acho que isso é importante, sem dúvidas, porque existem especificidades, mas esse é o tipo de multiculturalismo que não mobiliza a minha ação política, porque é um multiculturalismo para criar mercado consumidor, para criar nichos de mercado. Isso não faz parte de minha proposta transformadora do mundo, mas há quem ache que o mundo é isso mesmo e que vamos jogar o jogo dessa forma, criar esses nichos e espaços específicos para a população negra. Particularmente, eu tenho me vinculado muito mais a uma proposta de transformação da sociedade. Então, nesse sentido, prefiro pensar nesse jogo como um jogo com resultado aberto, 
sem garantias de resultados. E acho que os resultados das políticas de ações afirmativas dependerão muito da maneira como nós, os agentes sociais, vamos nos posicionar quais as leituras que estamos fazendo a respeito desse fenômeno, como estamos trabalhando com os/as nossos/as estudantes, qual é a qualidade da comunidade de diálogo que estamos estabelecendo. Então, eu gostaria de sinalizar para outras possibilidades, e vou fazer uma rápida volta para chegar ao ponto que eu gostaria de enfatizar aqui. Lembro um pouco das formulações do Boaventura de Sousa Santos - e isso está em alguns livros dele, mas, de uma maneira um pouco mais clara, em $A$ Gramática do Tempo: Para Uma Nova Cultura Política (2006) -, em que faz a crítica ao que ele chama de razão indolente. Com base nessa crítica, ele propõe uma racionalidade cosmopolita, vinculada a dois interesses: uma racionalidade cosmopolita que poderá expandir o presente e que, ao mesmo tempo, poderá contrair o futuro. Sobre expandir o presente, acho que já estamos vivenciando isso de alguma forma, que é o que ele chama de Sociologia das Ausências, que faz parte de todo esse processo de reflexão que temos na Sociologia, nas Ciências Sociais, de uma maneira geral, em que pensamos a teorização a partir das localidades - quer dizer, a grande crítica ao projeto eurocêntrico de formulação do conhecimento em que, a partir das particularidades europeias, criaram-se teorias com caráter universal. Acho que isso, cada vez mais, tem sido rebatido e confrontado por múltiplas experiências: seja, por exemplo, pelos grupo de estudos da subalternidade, que é um grupo maravilhoso de pensadores/as indianos/as; seja por intelectuais negros/as norte-americanos/as, sobretudo o feminismo negro norte-americano; pela contribuição latino-americana, sobretudo a contribuição andina; e também, a meu ver, pela contribuição de intelectuais negros/as no Brasil; pra não falar, é claro, da África e as grandes contribuições das várias Áfricas para a elaboração do conhecimento. Essas teorizações estão sendo produzidas, o que nos cabe é olhar para isso. Então, essa é uma dimensão do que Boaventura de Sousa Santos chama de Sociologia das Ausências. A segunda dimensão da qual ele fala é a Sociologia das Emergências, que é justamente a racionalidade capaz de contrair o futuro - ou seja, o entendimento de que o futuro não está contido no presente. Nesse livro, Santos (2006) faz uma crítica à razão proléptica, como um subcampo da razão indolente. Prolepse significa o conhecimento do futuro no presente. Ou seja, eu já sei o que vai acontecer amanhã porque as condições do futuro já estão dadas hoje. A razão proléptica é aquela 
que julga que sabe tudo a respeito do futuro e concebe o alcance do futuro como um processo linear, uma atualização automática do presente. Eu acho que esse é um ponto que necessita do investimento de nossa energia, não só no Brasil, mas no mundo, como um todo, porque, a meu ver, se me permitam ser muito direto, a gente precisa, urgentemente, de uma reelaboração, de uma crítica ao socialismo, ao projeto socialista, e uma reelaboração de uma outra perspectiva futura. $E$ isso não significa uma adesão a essa lógica de mercado ou coisa que o valha. Não é isso. Estou pensando, muito mais, num projeto anticapitalista, e que acho que é um projeto que não se dá pela formulação socialista, porque o socialismo padece, também, do conhecimento eurocentrado, do eurocentrismo, de um conhecimento formulado a partir de experiências locais europeias que passam a ser universalizadas, e que, portanto, têm de ser adotadas no Brasil, têm de ser adotadas nos Andes, na China, na África do Sul etc. Esses outros locais têm inteligência suficiente para elaborar projetos, então, a gente tem que se dedicar a essa reflexão também. Nesse sentido, voltando ao diálogo com a Nancy Fraser, eu diria que o futuro está aberto e dependerá das correlações de forças e da possibilidade de mobilizarmos as coletividades ou nos mobilizarmos como coletividade para definir o mundo de amanhã.

Podemos pensar as ações afirmativas não somente na chave de remédios afirmativos, mas também como remédios transformativos, que podem ser esse espaço de renovação das universidades - e digo renovação das universidades porque até hoje ainda não conheço outra instituição melhor habilitada para se pensar o país e para elaborar projetos nacionais do que as universidades. É claro que isso pode se dar no âmbito dos partidos políticos, no âmbito dos movimentos sociais, mas acho que a universidade tem essa característica. Os/As alunos/as beneficiados/as direta ou indiretamente pelas ações afirmativas podem ser pessoas que tragam uma outra razão, outras experiências, outras perspectivas cosmológicas - como, por exemplo, os/as estudantes indígenas que chegam à universidade -, e com isso, a gente talvez possa diversificar as possibilidades do nosso futuro. Podemos, então, nesse sentido, pensar em outras perspectivas transformativas que não se dão unicamente no âmbito do socialismo. Escutando alunos/as negros/as e indígenas, e alguns/algumas professores/as e intelectuais negros/as e indígenas - e me parece que isso é muito mais forte entre os/as indígenas -, vi que a caracterização dessa nossa civilização, essa 
civilização que se forma com o sistema-mundo moderno/colonial, desde o século XVI, é uma caracterização que a equivale a uma civilização de morte, em que o planeta sequer tem condições de suportar os níveis de extração de riquezas da terra. As ações afirmativas podem ser um caminho para formar quadros da população negra brasileira, das populações indígenas brasileiras - quadros que podem pensar nessa superação da atual crise civilizatória na qual estamos.

Resgatando o caráter transformativo de tais políticas, gostaria de conectar essa discussão sobre ações afirmativas no Brasil com uma perspectiva internacional. Usando uma expressão de Fanon, compreendo que seja necessária uma união dos condenados do mundo - 'condenados da terra, uni-vos!' E aí, nesse sentido, não somente populações negras brasileiras, populações indígenas, mas asiáticos, africanos unidos para a elaboração de um novo projeto utópico de vida. Em 1955, houve a famosa Conferência de Bandung, na Indonésia, que reuniu líderes e intelectuais daquilo que ficou conhecido como o Terceiro Mundo - eram líderes e intelectuais terceiro-mundistas. Hoje nós estamos precisando de uma nova Conferência Mundial para se pensar no compartilhamento de experiências e elaboração de novos projetos políticos que inspirem a nossa ação. Precisamos de uma nova utopia. Eu, então, gostaria de pensar as ações afirmativas no campo das políticas utópicas também. Assim, para concluir, acho que o jogo está em aberto. Acho que simplesmente falar que as ações afirmativas seriam um remédio afirmativo que confirmaria o modelo liberal do Estado e, portanto, seriam enquadradas como um multiculturalismo liberal, é uma possibilidade, e penso que se fizermos isso já teremos alguns avanços, no sentido de colocar a população negra em espaços em que ela nunca esteve. Mas acho que esse é o futuro em aberto. As ações afirmativas podem, também, significar uma politização do conhecimento - uma politização no bom sentido -, e uma capacitação de quadros para se pensar o futuro. A elaboração desse futuro, de um projeto utópico, não é um projeto utópico que se elabora simplesmente em uma dimensão nacional. Hoje, cada vez mais, estamos vendo como estamos entrelaçados por essa grande sociedade em rede. Portanto, precisamos também de uma resposta internacional, global, a esse fenômeno, para alimentar nossas mentes e esperanças. 
Prof. Doriam Borges: Em sua opinião, por que os negros representam $74,4 \%$ das vítimas da violência letal no Brasil (Anuário do Fórum Brasileiro de Segurança Pública 2020)? Quais as causas desses assassinatos e que atores estão envolvidos nessas mortes?

Prof. Joaze Bernardino-Costa: Esses dados do Fórum Brasileiro de Segurança Pública são extremamente trágicos e tristes. A cada dia que passa a gente se depara com cenas de violência pública que são extremamente estarrecedoras. Todos nós estamos impactados com essas imagens que estão circulando da violência praticada num supermercado no Rio Grande do Sul. De fato, eu não sei para quem é a segurança pública da qual estamos falando. Talvez a gente esteja falando de insegurança pública para a população negra, porque como você disse, $74 \%$ das vítimas de violência letal no Brasil são pessoas negras. Tive acesso aos dados do Fórum de Segurança Pública: 66,7\% da população carcerária é composta por pessoas negras. No ano passado, por exemplo - e esse é outro dado extremamente chocante -, 35 mil pessoas negras foram assassinadas no Brasil. É o que equivale a um estádio do Pacaembu cheio. Então, são coisas chocantes. E, ao mesmo tempo, isso não é uma exclusividade do homem negro, já que a mulher negra também é vítima de outras formas de violência, sendo a maioria das vítimas da violência sexual e da violência doméstica. As causas são múltiplas e complexas. Isso envolve pensar, mais uma vez, a sociedade brasileira. A tese da colonialidade do poder fala da centralidade da raça, e em como, mesmo após a Independência do Brasil, continuamos vinculados, de maneira colonial, às nações externas, mas, sobretudo, nos faz questionar sobre como as relações sociais que foram forjadas no período colonial sobrevivem num Brasil independente e republicano. Essa é uma história também muito mal resolvida do ponto de vista global - basta ver o que está acontecendo no mundo: nos Estados Unidos, com o Black Lives Matter; em vários países europeus; na maneira como a África se enquadra na geopolítica mundial. Mas, no Brasil, acho que é um problema com questões mais profundas a serem ainda resolvidas.

Eu buscaria uma explicação sobre isso a partir da tese da Sueli Carneiro (2005). E qual é a forma de argumentação da Sueli Carneiro? Ela estabelece um diálogo com Foucault e, a meu ver, antecipa algumas teses e colocações que são expostas, hoje, por Achille Mbembe (2018). E nesse diálogo com o Foucault ela vai utilizar a ideia de 
dispositivos de poder. E ela vai falar de dispositivo de racialidade, entendido como um conjunto heterogêneo de discursos, instituições, organizações arquitetônicas, medidas administrativas, leis e proposições filosóficas que dão origem e que conformam uma sociedade. Então, aqui, o que temos no Brasil é uma heterogeneidade - esse dispositivo de racialidade que se configura a partir desse conjunto heterogêneo de discursos que justificam práticas racistas e a discriminação racial. Esse dispositivo de racialidade produz a verdade sobre o outro.

Só abrindo um parêntese, eu acho que é muito interessante, como a Sueli Carneiro fala, também, da importância do dispositivo de racialidade para se pensar as formas arquitetônicas. E esse fenômeno mundial de derrubada de estátuas que, aliás, não começa na Inglaterra e nos Estados Unidos, pois já havia tido um movimento anterior na África do Sul, talvez em 2014, na Universidade de Cape Town, de derrubada da estátua do Cecil Rhodes, um dos importantes patronos da colonização da África do Sul, quando estudantes começaram o movimento chamado de Rhodes Must Fall (Rhodes Deve Cair). Depois, esse movimento se tornou Fees Must Fall (Taxas Devem Cair), quando começaram a negociar a redução ou a derrubada do preço das mensalidades nas universidades sul-africanas. Então, acho interessante como esses dispositivos de racialidade também se constituem a partir das formas arquitetônicas. Em quantas cidades brasileiras existem, por exemplo, uma homenagem a uma personalidade indígena ou a uma personalidade negra? Você tem, no máximo, um busto do Zumbi dos Palmaresem Brasília, no Rio de Janeiro, em outra cidade, mas todos os outros espaços são marcados pela branquitude. Esta também é uma maneira de construir os dispositivo de racialidade. Ou seja, os espaços públicos não são, a princípio, espaços para a reafirmação da identidade negra.

Mas, voltando à ideia do dispositivo de racialidade que a Sueli Carneiro constrói, para tentarmos entender esse fenômeno da maior vitimização da juventude negra por modos violentos - seja por parte do Estado, seja em confrontos na própria sociedade. Este conceito é importante para entendermos como é que se constrói um discurso sobre o outro. E esse dispositivo de poder, esse dispositivo de racialidade, por sua vez, se junta com a ideia do poder soberano. Não poderei articular isso aqui em detalhes - e isso, tanto a Sueli Carneiro quanto o Achille Mbembe (2018) já o fazem muito bem -, mas é a ideia do poder soberano do Estado que se constitui, em última instância, como o direito 
de fazer morrer e o direito de fazer viver. Do ponto de vista teórico, eu diria que essas ideias, o dispositivo de racialidade e o poder soberano - sobretudo o direito de fazer morrer (portanto, a necropolítica) -, se juntam e são articulados por aquilo que nós temos nomeado como racismo estrutural e racismo institucional, ou seja, em última instância o Estado decide quem deve viver e quem deve morrer. E essa decisão do Estado não se dá simplesmente pela ação do Estado, mas se dá pela inação do Estado. E isso também é importante situar. A inação do Estado está, muitas vezes, comprometida com o racismo estrutural. A omissão do Estado também é um dado desse racismo estrutural. Vejamos um exemplo que a Sueli Carneiro traz na tese dela: a baixa assistência médica à população negra ou doenças que incidem em maior proporção sobre a população negra ou a ausência de pré-natais e, até mesmo, de pós-natais disponíveis para as mulheres negras. Isso gera um número de complicações ligadas ao parto, à geração da vida, que resulta em sérios problemas, resultando, no limite, nas morte das mulheres negras. A inação do Estado é também responsável por essas mortes. É o 'deixar morrer' por parte do Estado.

Então, voltando à sua pergunta, eu acho que essa explicação, do campo da hegemonia, do campo das ideias, é muito importante para a gente entender o que está acontecendo na rua, na maneira como o policiamento é feito no Brasil. A sobrevivência ou a existência de policiamento, de vigilância privada, sem nenhuma regulamentação na sociedade brasileira. A gente sabe que, por exemplo, aquilo que vimos nessas imagens que estão circulando nas mídias jamais aconteceria se a pessoa fosse branca. E por quê? Porque o corpo branco é merecedor de um respeito, é merecedor de uma sacralidade. Porque, do ponto de vista ontológico - e daí, então, a ideia da Sueli Carneiro, da construção do paradigma do outro como não-ser -, esse corpo branco é qualificado e entendido como um ser. Enquanto que o não-ser, o sub-humano, ou não humano, é o corpo negro, que pode ser violado, pode ser alvo da violência, e isso não causa indignação por parte das pessoas. Então, acho que tem, primeiro, uma explicação no campo ideológico, no dispositivo de racialidade, que nos permite entender essa sociedade a partir da raça. Este é um elemento constitutivo do nosso dia a dia.

A famosa frase de Fanon (2005: 105): "Mamãe, olha o preto! Mamãe, olha o preto! Estou com medo! Estou com medo!", quantas crianças brasileiras já não devem ter pensado ou falado isso ao cruzarem com uma pessoa negra? Começa-se desde tenra 
idade a desenvolver uma visão acerca do corpo negro, da identificação da pessoa negra com o perigo. Então, acho que ocorre isso nessa dimensão do pensamento, do domínio hegemônico, se a gente quiser pensar a partir das contribuições de Patricia Hill Collins (2019). A autora de Pensamento Feminista Negro fala de quatro domínios da matriz de poder ${ }^{5}$, um desses domínios é o domínio hegemônico, e como isso ocorre nas nossas cabeças. Uma outra dimensão é a estrutural, ou institucional. As instituições são construídas para fazer o que fazem. Quando, por exemplo, a gente vê excessos policiais, não é porque a pessoa que está cometendo aqueles excessos não deveria estar cometendo aquilo. Ela é treinada para, justamente, cometer aqueles excessos. Quando a gente verifica esses excessos de uma maneira sistemática é porque o treinamento é exatamente aquele. Não é que a pessoa não teve perícia para exercer o seu ofício. Então, as instituições são construídas para agir daquela maneira. O mais grave nessa história é que o racismo é tão forte e penetra tão profundamente nas instituições que o próprio agente negro, o próprio policial negro, ou segurança negro, ou o próprio negro, concebem o mundo daquela maneira também. Angela Davis, no livro A Liberdade é Uma Luta Constante (2018), fala sobre um documentário que ela viu sobre a África do Sul, de um confronto da polícia debelando uma manifestação de trabalhadores mineiros sindicalizados. E aquele confronto rendeu ferimentos e mortes entre os manifestantes negros. Os policiais eram negros e a polícia era operada por uma mulher negra. Então, veja como isso é complexo. Acho que esse é o nosso drama: a impossibilidade de dizer que o racismo está somente no branco. Não! O racismo está nas instituições. Como sociólogos, precisamos começar a fazer essa discussão no plano das instituições. As instituições e a sociedade são "brancas". Supermercados contratam, de forma legal ou ilegal, agentes para fazer segurança privada, portanto, estes começam a participar dessa cadeia de produção de violência, da mesma forma como a polícia também comete os seus excessos contra a população negra. E nós, como sociedade, não nos revoltamos contra isso, achamos normal, porque, de alguma forma, estamos anestesiados pelo racismo. A cena do Rio Grande do Sul é mil vezes mais agressiva do que a cena do policial colocando o joelho no pescoço do cidadão negro norte-americano. Na cena que reacendeu o movimento black lives matter, podemos até imaginar que o polícial não viu

\footnotetext{
5 Os quatro domínios da matriz do poder são os seguintes: estrutural, disciplinar, hegemônica e interpessoal.
} 
que George Floyd estava sendo sufocado e que morreu naquele momento. Agora, no caso do Rio Grande do Sul, são desferidos golpes. A cena é de uma extrema brutalidade. E qual é a nossa reação? Quando não nos levantamos contra isso, quando não vamos para a rua, quando não iniciamos um movimento coletivo de protesto, nós também estamos sendo omissos. Nesse sentido, não é só o Estado. Nós também, de alguma forma, participamos disso aí. Acho que esse é um drama que a gente vive como sociedade brasileira, e nós, sociólogos, estamos olhando isso e tentando interpretar esse fenômeno. Acho que sua pergunta é merecedora de teses e mais teses nas nossas áreas do conhecimento. Mas, por ora, eu apontaria essa explicação na ordem do pensamento, na ordem das instituições, como explicação possível para números tão gritantes de violência contra a população negra.

\section{Prof. Doriam Borges: 0 que poderia ser feito para mudar este cenário, considerando um contexto político de discurso conservador, que expressa uma filosofia na qual, para reduzir a violência, é necessário aplicar mais violência através do braço armado do Estado?}

Prof. Joaze Bernardino-Costa: Acho que analisar esse contexto político, de emergência desse discurso conservador, é um desafio, porque isso exige, antes de tudo, uma resistência emocional da nossa parte. Eu escrevi um artigo, recentemente, sobre o recrudescimento do racismo e a ascensão da nova direita no Brasil ${ }^{6}$. Fiz o trabalho, que é necessário, analisando o discurso da extrema-direita nas mídias sociais (Twitter, Facebook, Instagram), e encontrei um absurdo de argumentações rasas e, ao mesmo tempo, conclusivas. E é isso que é o mundo virtual. Não é um espaço de elaboração de argumentos. As pessoas chegam muito rápido às conclusões. As pessoas são muito propositivas - querem saber o que têm que fazer. E, em um desses grupos, um cluster de atores e de organizações em torno da segurança pública, o tom é o seguinte: para resolver o problema da segurança pública é preciso recrudescer a justiça penal. Então, o que se vê são slogans tais como: "a única pena que você tem que ter do bandido é a pena de morte", "se estiver com pena do bandido leve-o pra casa". Enfim, chavões que

\footnotetext{
${ }^{6}$ Bernardino-Costa, Joaze. Abrindo a Caixa de Pandora: a extrema direita e o recrudescimento do racismo. Sairá publicado num número especial na revista Latin American Perspectives
} 
a gente escuta e que estão aliados à 'bancada da bala' no Congresso Nacional. Quer dizer, há uma forte estruturação disso aí. O enfrentamento disto só pode se dar a partir das formas coletivas.

Pensando um pouco do ponto de vista teórico, e me apoiando novamente em Achille Mbembe (2017), o que a gente assiste é à difusão de uma política de inimizade, da construção daquele que diverge de mim como um inimigo. Este é um cenário que está diante dos nossos olhos. A oposição política não é mais tratada como alguém que está na arena do debate, na arena do diálogo, mas é colocado na arena do inimigo, e, portanto, deve ser eliminada.

Uma outra questão que a gente precisa colocar, efetivamente, é que boa parte da população encarcerada encontra-se nessa situação por crimes de pequena periculosidade, sendo pessoas que poderiam estar livres. Aí voltamos à primeira questão desta entrevista: uma das bandeiras do movimento negro tem sido a bandeira pela redução do encarceramento da população negra, que a Angela Davis chama de abolicionismo prisional, abolicionismo penal (2018). E esse é um discurso que ainda não grassou campo na sociedade brasileira, ficando restrito a um grupo pequeno de pessoas. Mas acho que, mais do que nunca, é fundamental a gente colocar a bandeira do antiproibicionismo como uma bandeira política, uma bandeira política do movimento negro. Aí eu tenho que me aliar ao Fernando Henrique Cardoso: se a maneira de enfrentar o tráfico de drogas é pelo recrudescimento de leis penais, já perdemos essa luta há muito tempo, isso está óbvio, estampado diante dos nossos olhos. Então, a gente precisa reinventar a maneira de lidar com isso e a reinvenção disso tem um impacto direto sobre a população negra. Porque são jovens negros que são cooptados pelo tráfico e que estão lá por falta de perspectiva no mercado de trabalho. Efetivamente, a pessoa fez daquilo um emprego, e isto não quer dizer que ela seja uma ameaça pública que justificasse o seu encarceramento. Voltando ao que eu dizia anteriormente, penso que é fundamental a gente colocar na rua, na praça pública, a ideia do abolicionismo prisional como uma maneira de contrapor essa vertente de armar o Estado. E o que é o abolicionismo prisional? Há uma seção do mesmo livro da Angela Davis, A Liberdade é Uma Luta Constante, em que ela fala o seguinte: se nós detectamos que a maior parte da população presa é formada por pessoas negras, então, isso é um indício de que há um claro problema de racismo na sociedade; se nós detectamos que a maior parte da 
população carcerária é uma população analfabeta, ou semianalfabeta, há um problema sério no sistema educacional dessas sociedades; se constatamos que boa parte das pessoas que estão encarceradas - este é um caso típico dos Estados Unidos - é formada por pessoas que se endividaram por problemas ligados a tratamento de saúde, então, há claros problemas na política de assistência à saúde daquela população. Portanto, devemos pensar no racismo, no analfabetismo e nos problemas ligados à saúde naquele contexto. Da mesma forma, acho que a bandeira do abolicionismo penal no Brasil pode ser colocada dessa forma. Se nós constatarmos que existe uma presença maior da população negra nas cadeias brasileiras, a questão de fundo, que está justificando cadeias superlotadas, é o racismo que existe dentro da sociedade brasileira. Portanto, a gente precisa atacar o racismo dentro da sociedade brasileira. Se constatarmos que boa parte das pessoas são pequenos traficantes, é necessário a gente mudar a política de drogas do país; tratar isso, talvez, como uma questão de saúde e não como uma questão de segurança pública.

Acho que o enfrentamento é coletivo e precisamos, também, oferecer alternativas. Quais as alternativas propostas, do ponto de vista político, ao discurso da segurança pública que tende a matar ou encarcerar a população negra? Qual é o discurso que a gente pode construir como alternativa a isso? Acho que esse enfrentamento se dá por esse discurso e se dá por formas coletivas de enfrentamento desse problema.

E, aqui, eu adicionaria algumas complexidades desse cenário. A professora Thula Pires (2015) apresenta dados e relatos surreais sobre o encarceramento de mulheres negras. Muitas mulheres são tipificadas como traficantes por tentarem levar drogas para as prisões, mas, em muitos casos, o que as "obrigam" a fazer esse tráfico é a ameaça que o seu filho ou seu marido estão sofrendo na prisão. Então, para que eles não sejam mortos lá dentro, a mulher faz esse trabalho de transporte de drogas para o interior da cadeia. Acho que a questão é muito complexa, mas o fato é que, se continuarmos tratando a questão da maneira como estamos tratando, teremos que construir muitas cadeias, porque as pessoas já não cabem mais nas que existem. É necessário repensar como tratar a questão e, sobretudo, repensar o marco regulatório em relação à tipificação de quem é traficante, de quem é usuário, de como se dão essas 
tipificações. Essa, sem dúvida, é uma bandeira fortíssima do movimento negro e ela precisa ganhar peso, porque é estrutural e central na sociedade brasileira.

Profa. Maria Railma Alves: Quais os avanços teóricos e metodológicos que os pesquisadores da "rede internacional de pesquisa sobre práticas de racialização e promoção da igualdade racial no Brasil, África do Sul, Reino Unido e Suécia” têm construído? É possível apontar um modelo de análise sobre as práticas de racialização e promoção da igualdade entre os países pesquisados?

Prof. Joaze Bernardino-Costa: É uma pergunta muito boa e merecedora de um curso. Vou contar um pouco dessa pesquisa e, depois, tentarei responder mais pontualmente o que você está perguntando. Essa pesquisa nasce da minha participação em uma conferência na Universidade de Leeds, na Inglaterra, cujo título era Construindo Universidades Antirracistas. Para tal conferência eu me encontrei, pela primeira vez, com a Shirley Tate - que hoje se tornou uma amiga - e com o lan Law. Além deles, fiz contato com algumas pessoas da África do Sul, dos Estados Unidos e da Austrália. Tivemos um desdobramento daquela conferência. Foi um encontro muito rico, que rendeu publicações na revista Race, Ethnicity and Education ${ }^{7}$, e o dossiê organizado a partir dos artigos foi bastante acessado pelas pessoas, transformando-se num livro. Num segundo momento, um professor na Suécia, que não estava no grupo inicialmente, tinha disponível uma verba de projeto da Academia Sueca de Ciências, e montamos esse projeto para comparar essas quatro realidades (Brasil, África do Sul, Suécia e Reino Unido), pensando, principalmente, sobre práticas de racialização e práticas de desracialização nesses contextos, com foco, especificamente, nos últimos cinco anos. 0 projeto começou em 2017, buscando tematiza os acontecimentos a partir de 2014 até o presente.

Em geral, o que vemos mais frequentemente é um olhar voltado para o Brasil da década de 1930, da década de 1950, 1970, mas o que está acontecendo agora no Brasil? Esta é uma das perguntas centrais da pesquisa. Isso tornou o projeto muito interessante,

\footnotetext{
${ }^{7}$ Race, Ethnicity and Education, vol. 20, n. 3, May 2017 (Special issue: Building the Antiracist University).
} 
porque ninguém esperava que passássemos por esses últimos cinco anos, com esse cenário brasileiro (um golpe político, a ascensão da direita que, depois, 'pavimenta a estrada' para a extrema-direita, e essa extrema-direita articulada em escala internacional com outros partidos e outros governos de extrema-direita etc). Quer dizer, um cenário que não imaginávamos! E é um cenário, também, que fez com que emergisse um discurso que nós não acreditávamos que existisse no Brasil, um discurso abertamente racista. O que temos assistido no Brasil, do ponto de vista da análise sociológica, evidencia coisas que a gente não acreditava. Eu me lembro que, nos anos 2000, quando eu falava de racismo no Brasil, as pessoas retrucavam e diziam que aquilo era uma invenção do movimento negro, pois éramos um país de gente harmônica e amigável! E agora descortinou absolutamente tudo. Para a nossa tristeza, a gente descobre que existe um discurso abertamente racista entre nós.

As análises feitas Inglaterra revelam coisas semelhantes. Lá está em vigor um no processo de racialização de cunho religioso. Incide um racismo sobre a população muçulmana. Na Suécia existe uma racialização, também, contra ciganos - pessoas de pele branca, mas que são racializadas - e contra migrantes africanos, asiáticos e, principalmente, contra migrantes árabes provenientes do Oriente Médio. O Brexit e suas consequências em termos de racialização também tem sido estudado. O Brexit coloca na ordem do dia as discussões sobre nacionalismo inglês e suas repercussões sobre a definição de quem é inglês. A Suécia é um caso muito singular, um país muito interessante, mas com uma extrema-direita também muito forte, com a produção de um discurso racista muito forte, que se mescla a argumentos eugênicos. E a África do Sul, com todo esse cenário pós Nelson Mandela, de ascensão do Congresso Nacional Africano, desde 1994 no poder, a formação de uma elite negra; como ficam os coloureds na África do Sul, as pessoas de origem indiana, de origem asiática?

O cerne do nosso projeto de pesquisa é entender os processos de racialização, como eles se dão hoje, se eles são, simplesmente, continuidade do nosso longínquo passado ou se têm ingredientes novos. Sobre a desracialização, esse é um conceito que não tem muita adesão no Brasil e na África do Sul - isso se dá muito mais na Inglaterra e, talvez, na Suécia. Este conceito remonta à ideia de desfazer os vínculos desumanizadores que deram origem às populações negras, às populações indígenas, e a todas as populações minorizadas. Do ponto de vista das políticas públicas, a questão 
é: como tornar a categoria racial em uma categoria insignificante do ponto de vista social? A partir da modificação das relações de poder, sobretudo, das relações de propriedade, de privilégios e de poder. Então, só é possível falar em desracialização no momento em que a gente modificar essas estruturas, quando houver transformações estruturais na sociedade. Do contrário, isso é apenas um escamoteamento dos problemas raciais, tal qual nós fizemos aqui no Brasil durante a vigência do mito da democracia racial. Ou seja, não se fala de raça, mas as relações de poder continuam sendo fortemente marcadas, do ponto de vista racial. Assim, a ideia de desracialização é essa: uma desconstrução das relações racializadas, mas, sobretudo, porque mudamos, mexemos, nas relações de poder. E mexemos como? A partir de políticas públicas que mexam, efetivamente, na estrutura da sociedade, na economia, na política, nas coisas centrais da sociedade. Sem isso não tem como falar em desracialização. Esse é um diálogo que a gente estabeleceu na nossa pesquisa. Entretanto, esse conceito de desracialização ainda fica como algo muito mais do campo de especialistas em relações raciais do que, propriamente, do campo do ativismo e do movimento social. Por exemplo, a gente não fala de políticas desracializadoras no Brasil, mas fala de políticas antirracistas. Então, a ideia de antirracismo é uma ideia que tem mais adesão no contexto brasileiro do que o conceito de desracialização. Do ponto de vista teórico, este projeto de pesquisa tem como contribuição uma reflexão sobre os conceitos de desracialização, racialização, antirracismo, e, por sua vez, um descarte, por completo, da ideia de pós-racialismo, que havia sido colocada quando houve a eleição do Obama e passou-se a falar que estávamos entrando numa era pós-racial.

Do ponto de vista metodológico, eu diria que essa pesquisa continua sendo um desafio. Ela se baseou em entrevistas com lideranças e policy makers, tanto no Brasil quanto nos outros contextos nacionais. Tive a oportunidade de entrevistar praticamente todo o staff central da SEPPIR (Secretaria Especial de Políticas de Promoção da Igualdade Racial) do governo Lula e do governo Dilma, e algumas pessoas do governo Temer, para saber o que essas pessoas estavam pensando em termos de políticas públicas, de elaboração dessas políticas. E a pesquisa também se baseou em análises legislativas, análise de matérias jornalísticas, e ainda, no universo das mídias sociais. E os outros colegas também fizeram isso nos seus respectivos contextos. Essa 
pesquisa, fazendo uma propaganda, também vai resultar num livro a ser publicado em inglês, comparando as quatro experiências.

Profa. Maria Railma Alves: Considerando os seguintes avanços envolvendo a temática racial no Brasil, dentre eles: criminalização do racismo - que ganha ênfase na Constituição Federal, especialmente no Capítulo I, que trata "Dos Direitos e Deveres Individuais e Coletivos" - Art. V, inciso XLII: "a prática do racismo constitui crime inafiançável e imprescritível, sujeito à pena de reclusão, nos termos da lei" (BRASIL, CFB/1988); a Lei $n^{\circ} 10.639 / 2003$, resultado da luta de educadores e ativistas do Movimento Negro no Brasil, que trata da obrigatoriedade do ensino da História e Cultura Afro-Brasileira nos estabelecimentos de ensino fundamental e médio; a Lei ${ }^{\circ}$ 12.288, de 20 de julho de 2010, que Institui o Estatuto da Igualdade Racial, e também a Lei $n^{\circ} 12.711 / 2012$ (Lei de Cotas). Qual avaliação e quais perspectivas o senhor apresentaria?

Prof. Joaze Bernardino-Costa: Apoio-me para responder a essa pergunta num debate que ocorreu num seminário na Fundação Carlos Chagas, quando estávamos avaliando os avanços da Lei de Cotas (12.711). E uma pessoa na plateia estava falando que a política de cotas deveria ser mais comprometida com a questão racial em si. Estava fazendo crítica à ideia de que a questão racial se tornou um terceiro critério dentro da política de cotas - em primeiro, escola pública; depois, renda per capita de até um salário mínimo e meio; e, depois, pretos, pardos e indígenas, de acordo com a proporção dessas pessoas na unidade da federação em que a Universidade está situada. Essa é a maneira como a lei está construída. Então, a pessoa começou a se lamentar, dizendo que a lei deveria ser diferente. E eu gostei muito da resposta do André Lázaro, então Subsecretário do MEC na gestão do Fernando Haddad. Ele falou que achava que a gente tinha que aprender a celebrar e a comemorar, e que a lei é um avanço, e se a gente olhar do ponto de vista matemático ela significa um aumento do número de vagas para alunos negros nas universidades brasileiras. Então, isso, por si só, é motivo para comemorar. Poderia ser diferente? As coisas sempre podem ser diferentes. Pego essa fala do André Lázaro pra falar isso. Essas leis poderiam ser diferentes? Poderiam. 0 
Estatuto da Igualdade Racial poderia ter um Fundo para a igualdade racial, que era o que estava previsto? Poderia. Mas tudo isso significa um avanço. Acho que isso é resultante de uma militância longa, constante, e de uma dedicação de ativistas negros/as e antirracistas que permitiram a construção desse novo marco regulatório na sociedade brasileira. Ainda temos muita coisa a fazer, mas acho que é com base nisso que temos pequenos avanços. Nós, que somos professores/as universitários/as, somos impactados/as diretamente por essas políticas. E a constatação disso é muito fácil, não é? Por exemplo, estou numa Universidade onde eu estive como aluno de graduação, de Mestrado, de Doutorado, saí durante um tempo e hoje sou professor. Essa Universidade em que sou professor hoje é completamente diferente daquela em que eu era aluno. Mesmo com todos os desacertos da política de cotas, ela está proporcionando oportunidades únicas para gerações de alunos negros, não é? Não só ela, mas a lei $10.639 / 2003$ e a lei $11.645 / 2008$, que trouxeram a obrigatoriedade de incluir no currículo da educação básica a contribuição dos povos negros e indígenas. O conjunto de leis que você menciona são avanços muito consistentes e importantes para a população negra, para a construção de uma sociedade antirracista. E, fazendo coro a uma frase do Aimé Césaire (1957), ele fala que há duas maneiras de a gente se perder: a gente se fechando em uma particularidade, como se fosse um gueto, ou se perdendo no universalismo, não tendo a nossa identidade. Esse conjunto de leis, os avanços que nós estamos colocando aqui, não são, de maneira alguma, uma defesa do identitarismo ou coisa que o valha, mas acho que é uma maneira de não nos perdermos dentro desse cenário que se constrói. É a gente se colocando como atores sociais que têm raízes, que têm experiências, que têm histórias particulares a partir das quais nos posicionamos nesse mundo. Mas, ao mesmo tempo, também, é uma oportunidade para nos colocarmos no mundo, podendo contribuir com o mundo, dotando-o de sentido, não é? Citando Fanon (2005, p. 103), que é um dos meus livros de cabeceira, ele fala: "cheguei ao mundo pretendendo descobrir um sentido nas coisas, minha alma cheia do desejo de estar na origem do mundo, e eis que me descubro objeto em meio a outros objetos". Eu acho que essas lutas são lutas pra nos colocarmos como seres e restaurarmos a nossa capacidade de contribuir com o mundo e dotar o mundo, também, de sentido. E pra isso é necessário que a gente saiba quem nós somos a fim de que possamos pensar nesses projetos universais sem perdermos as nossas identidades. É aquilo que Ramón 
Grosfoguel (2016) quer dizer quando fala de construir um pluriversalismo, um universo que tenha várias diferenças e que tenha espaços para essas diferenças. Sempre com a esperança de que a gente possa, efetivamente, ter um mundo um pouco mais justo, caracterizado por solidariedade, por igualdade, e que as pessoas possam existir a despeito da sua cor ou da sua raça.

\section{Transcrição e revisão: Fernando Rodrigues Oliveira}

\section{Referências}

BERNARDINO-COSTA, Joaze. Saberes Subalternos e Decolonialidade: os sindicatos das trabalhadoras domésticas no Brasil. Brasília: EdUnB, 2015.

CARNEIRO, Sueli (2005) A construção do outro como não-ser como fundamento do ser. (Tese de Doutorado - Programa de Pós-Graduação em Educação, Universidade de São Paulo).

CÉSAIRE, Aimé. Lettre á Maurice Thorez. Paris: Presence Africaine, 1957.

COLLINS, Patricia Hill. Pensamento Feminista Negro. São Paulo: Boitempo, 2019.

DAVIS, Angela. A Liberdade é uma Luta Constante. São Paulo: Boitempo, 2018.

COX, Oliver C. Caste, Class and Race: a study in social dynamics. New York: Doubleday and Company, 1948.

COX, Oliver C. The foundations of capitalism. London: Peter Owen, 1959.

ELLISON, Ralph. Invisible Man. New York: Vintage Books, 1980.

FANON, Frantz . Pele negra, máscaras brancas. Salvador, EdUFBA, 2008.

FOUCAULT, Michel. Em Defesa da Sociedade. São Paulo: Martins Fontes, 2002.

FRASER, Nancy. "Da redistribuição ao reconhecimento? Dilemas da justiça numa era póssocialista". Cadernos de Campo, São Paulo, n. 14/15, p. 231-239, 2006.

GONZALEZ, Lélia. A categoria político-cultural de amefricanidade. Tempo Brasileiro. Rio de Janeiro, n. 92/93, jan./jun., 1988.

GROSFOGUEL, Ramon. "Para uma visão decolonial da crise civilizatória e dos paradigmas da esquerda ocidentalizada". In: Bernardino-Costa, Joaze; Maldonado-Torres, Nelson; Grosfoguel, Ramon (orgs.) Decolonialidade e Pensamento Afrodiaspórico. Belo Horizonte: Autêntica, 2018.

GROSFOGUEL, Ramon. A estrutura do conhecimento nas universidades ocidentalizadas: racismo/sexismo epistêmico e os quatro genocídios/epistemicídios do longo século XVI". Estado \& Sociedade, v. 31, n. 1, jan/abr. 2016, pp. 25-49.

HALL, Stuart. A questão multicultural. In: Sovik, Liv (org.) Da Diáspora: identidades $e$ mediações culturais. Belo Horizonte/Brasília: EdUFMG/ Unesco, 2003.

JAMES, C.R.L. Os Jacobinos Negros: Toussaint L'Overture e a revolução de São Domingos. São Paulo: Boitempo, 2000.

LUGONES, María. Colonialidad y género. Tabula Rasa, Bogotá, 9: pp. 73-101, julhodezembro, 2008.

MBEMBE, Achille. Políticas da Inimizade. Lisboa: Antígona, 2017. 
MBEMBE, Achille. Necropolítica: biopoder, soberania, estado de exceção, política da morte. São Paulo: n-1 edições, 2018.

NASCIMENTO, Abdias. "Quilombismo: um conceito emergente do processo históricocultural da população afro-brasileira". In NASCIMENTO, Elisa Larkin (Org.). Afrocentricidade: uma abordagem epistemológica inovadora. São Paulo: Selo Negro, 2009.

QUIJANO, Anibal. "Colonialidade do poder, eurocentrismo e América Latina". In: LANDER, Edgardo (org.). A colonialidade do saber: eurocentrismo e ciências sociais. Buenos Aires, Clacso, 2005. p. 227-278.

RAMOS, Alberto Guerreiro. Introdução crítica à sociologia brasileira. Rio de Janeiro, Editorial Andes limitada, 1957.

RATTS, Alex. Eu Sou Atlântica: sobre a trajetória e vida de Beatriz Nascimento. São Paulo: Instituto Kuanza/Imprensa Oficial, 2007.

SANTOS, Boaventura de Sousa. A Gramática do Tempo: para uma nova cultura política. São Paulo: Cortez, 2006.

PIRES, Thula Rafaela de Oliveira. "Do ferro quente ao monitoramento eletrônico: controle, desrespeito e expropriação de corpos negros pelo Estado Brasileiro". In: Flauzina, Ana; Freitas, Felipe; Vieira, Hector \& Pires, Thula (orgs.) Discursos Negros: legislação Penal, Política Criminal e Racismo. Brasília: Brado Negro, 2015.

WALLERSTEIN, Immanuel. The modern world-system, Vol. I. New York: Academic Press, 1974. 